(2) Open Access Full Text Article

ORIGINAL RESEARCH

\title{
Symptoms, Management and Healthcare Utilization of COPD Patients During the COVID-19 Epidemic in Beijing
}

This article was published in the following Dove Press journal: International Journal of Chronic Obstructive Pulmonary Disease

\author{
Ying Liang* \\ Chun Chang* \\ Yahong Chen \\ Fawu Dong \\ Linlin Zhang \\ Yongchang Sun
}

Department of Respiratory and Critical Care Medicine, Peking University Third Hospital, Beijing, I00191, People's Republic of China

*These authors contributed equally to this work
Correspondence: Yongchang Sun Department of Respiratory and Critical Care Medicine, Peking University Third Hospital, North Garden Road 49, Haidian District, Beijing, People's Republic of China

Tel +86 I3910979|32

Fax +86 1082266989

Email suny@bjmu.edu.cn
Background: Social distancing and restriction measures during the COVID-19 epidemic may have impacts on medication availability and healthcare utilization for COPD patients, and thereby affect standard disease management. We aimed to investigate the change of respiratory symptoms, pharmacological treatment and healthcare utilization of COPD patients during the epidemic in Beijing, China.

Methods: We conducted a single-center, cross-sectional survey performed at Peking University Third Hospital and recruited patients with COPD who were interviewed by phone call. Clinical data, including respiratory symptoms, pharmacological treatment, management and healthcare access before and during the COVID-19 epidemic from January 25 to April 25, 2020, were collected.

Results: A total of 153 patients were enrolled for analysis. Before the epidemic, $81.7 \%$ $(125 / 153)$ had long-term maintenance medication and ICS/LABA $(60.8 \%)$ and LAMA $(57.5 \%)$ were most commonly used. During the epidemic, 75.2\% (115/153) maintained their pharmacological treatment and $6.5 \%(10 / 153)$ had to reduce or stop taking medications, with a slight decrease of patients taking ICS/LABA (53.6\%) and LAMA (56.9\%). Most of the patients $[76.5 \%(117 / 153)]$ had a low symptom burden, with a CAT score $<10$ during the epidemic. Of 153 patients, 45 (29.4\%) patients reported worsening of respiratory symptoms but only $15.6 \%$ (7/45) sought medical care in hospitals, while the remaining expressed concerns about cross-infection in the hospital $(55.5 \%, 25 / 45)$ or had mild symptoms which were managed by themselves $(28.8 \%, 13 / 45)$.

Conclusion: During the COVID-19 epidemic in Beijing, most of our COPD patients maintained their long-term pharmacological treatment and had mild-to-moderate symptoms. Approximately, $30.0 \%$ of the patients experienced worsening of respiratory symptoms, but most of them did not seek medical care in the hospital due to concerns about cross-infection. Keywords: COVID-19, chronic obstructive pulmonary disease, exacerbation, management

\section{Introduction}

Coronavirus disease 2019 (COVID-19) is a highly contagious infectious disease caused by severe acute respiratory syndrome coronavirus 2 (SARS-CoV-2). To fight the pandemic, reallocation of healthcare resources may have negative impacts on the care of patients without COVID-19. In addition, measures to mitigate the transmission of COVID-19, such as social distancing and restrictions may also affect the standard care of patients with chronic diseases such as chronic obstructive pulmonary disease (COPD). 
COPD is a common chronic airway inflammatory disease characterized by persistent respiratory symptoms and airflow limitation. ${ }^{1}$ A large systematic review and metaanalysis estimated that there were 384 million COPD cases in 2010 , with a global prevalence of $11.7 \%$ in the population aging from 32 to 74 years. $^{2}$ In 2018, the China Pulmonary Health $(\mathrm{CPH})$ study reported that the prevalence of COPD was $13.7 \%$ in the population aged 40 years or older, and estimated that there were nearly 100 million cases in China. ${ }^{3}$ During the COVID-19 pandemic, studies have shown that COPD is a common comorbidity of COVID-19, contributing to the progression and worse outcome of this infectious disease ${ }^{4}$ and increases the risk of 28-day mortality for more than 2 folds. ${ }^{5}$ Furthermore, patients with COPD are mostly elderly and vulnerable to infection and transmission of SARS-CoV-2, and therefore need particular attention during the pandemic.

As contingency measures, experts and societies have proposed guidance on the management of COPD during the pandemic. ${ }^{6,7}$ However, these guidelines are largely based on existing guidelines and expert consensus because of the lack of relevant research data during the COVID-19 pandemic. Therefore, we conducted a cross-sectional study of symptoms, management and healthcare utilization of COPD patients during the COVID-19 epidemic in Beijing, aiming to provide data for implementing relevant treatment strategy of COPD during the pandemic.

\section{Patients and Methods Study Subjects}

This was a single-center, retrospective, cross-sectional survey by telephone call performed in Peking University Third Hospital. Patients were selected randomly from the COPD database in our hospital by the following inclusion criteria: 1) 40 years of age or older; (2) a history of at least 3 months of diagnosed COPD according to Global Initiative for Chronic Obstructive Lung Disease (GOLD) Report. ${ }^{1}$ Patients who refused telephone interview or had cognitive dysfunction such as vascular dementia, Alzheimer's disease were excluded. We used a design based on a table of random numbers to select a representative sample. Sociodemographic information and clinical data, including respiratory symptoms, pharmacological treatment, management and healthcare access before and during the COVID-19 epidemic from January 25 to April 25, 2020 , were collected. The changes of respiratory symptoms, pharmacological treatment and healthcare utilization of COPD patients during the epidemic were the major composite endpoints in this study.

\section{Questionnaire and Data Collection}

We conducted the study via telephone interview from April 28 to May 13, 2020. Prior to the investigation, the physicians participating in this study and dialing to the patients were required to attend a centralized training session. Any identifier to an individual patient, such as identification number and full name, was not collected. All data were inputted into a programmed database by two people independently for statistical analysis.

The interviewing physician would explain the aim of this survey, the amount of time required, and the confidentiality and permissions for the collection of data in plain language. Upon getting oral approval from the patients or their close relatives, the interviewer carried on asking the questions from a questionnaire designed by the experts in the Department of Respiratory and Critical Care Medicine, which covered the following items:

\section{Demographic Information}

Sex, age, ethnicity, height, weight, permanent residence, employment status, education level, medical insurances, and smoking status.

\section{Medical History Before the COVID-19 Epidemic}

History of COPD, the numbers of COPD exacerbations and hospitalizations due to COPD exacerbation in the previous year.

Medications, Management and Healthcare Utilization Before the COVID-19 Epidemic

Medications for COPD treatment included inhaled shortacting $\beta$-agonist (SABA), inhaled short-acting muscarinic antagonist (SAMA), inhaled corticosteroids plus longacting $\beta$-agonist (ICS/LABA), long-acting muscarinic antagonist (LAMA), and oral theophylline. Management and healthcare utilization included personal action plan, attending to COPD education program, seeking online consultation, and medical visits to hospitals.

\section{Medications and Healthcare Utilization of COPD}

During the COVID-19 Epidemic (from January 25 to April 25, 2020)

Maintenance therapy for COPD and the compliance, the causes of changes in maintenance medication, medicine prescription refill in outpatient visits, times of visit to any hospital during the epidemic and the causes of medical 
visits (getting prescription for COPD, review and assessment of disease, or worsening of respiratory symptoms), and online consultation.

\section{Respiratory Symptoms and Management During the COVID-19 Epidemic}

The modified Medical Research Council (mMRC) dyspnea scale $^{8}$ and COPD Assessment Test (CAT) ${ }^{9}$ were performed to assess the symptoms of COPD. Changes of respiratory symptoms were reviewed, including the patient's overall perception, respiratory symptom worsening and the patients' management of changes of symptoms.

\section{Statistical Analysis}

The data were analyzed anonymously. Continuous variables were expressed as median [25th, 75th percentiles] or mean \pm standard deviation. Categorical variables were expressed as numbers (\%). Unpaired $t$-test was performed to assess the differences between continuous variables. Chi-square test or Fisher exact test was performed for categorical variables. Statistical analyses were performed using SPSS software, version 19.0 (IBM, Armonk, NY, USA). Results were considered statistically significant at $P<0.05$.

\section{Results}

We contacted 218 patients from April 28 to May 13. Sixtyfive patients refused to accept the interview, and finally, 153 patients $(70.2 \%, 153 / 218)$ who completed the questionnaire were enrolled for analysis. None of them were infected by SARS-CoV-2. The median age of the patients was $71(65-80)$ years and $85.0 \%$ of the patients were male. Approximately $80 \%$ of the patients were current smokers or former smokers. Over $90 \%$ were urban residents and most of them had retired. Seventeen patients (11.1\%) had no medical insurance. The detailed demographic and socioeconomic data are shown in Table 1.

The median history of COPD was 5.0 years and the longest history was up to over 20 years. In our study, 24 patients $(15.7 \%)$ experienced exacerbation in the previous year before the epidemic and $7(4.6 \%)$ were frequent exacerbators. Eighteen patients $(11.8 \%)$ were ever hospitalized due to COPD exacerbation in the previous year. The medical history data are shown in Table 2.

Before the COVID-19 epidemic, 125 patients (81.7\%) had long-term maintenance medication for COPD. ICS/ LABA and LAMA were the most commonly used pharmacological therapy. Twenty-two patients (14.4\%) had
Table I Demographic, Socioeconomic and Medical Characteristics $(n=153)$

\begin{tabular}{|c|c|c|}
\hline Characteristics & $\begin{array}{l}\text { Median [25th, } \\
\text { 75th Percentiles] } \\
\text { or } n(\%)\end{array}$ & Range \\
\hline Age (year) & $71[65,80]$ & $47-92$ \\
\hline $\begin{array}{l}\text { Sex } \\
\qquad \text { Male } \\
\text { Female }\end{array}$ & $\begin{array}{l}130(85.0) \\
23(15.0)\end{array}$ & \\
\hline $\begin{array}{l}\text { Residence } \\
\text { Urban } \\
\text { Rural area }\end{array}$ & $\begin{array}{l}143(93.5) \\
10(6.5)\end{array}$ & \\
\hline $\begin{array}{l}\text { Education } \\
\text { Illiteracy } \\
\text { Primary school } \\
\text { Junior middle school } \\
\text { Senior middle school } \\
\text { University }\end{array}$ & $\begin{array}{l}2(1.3) \\
22(14.4) \\
52(34.0) \\
48(31.4) \\
29(18.9)\end{array}$ & \\
\hline $\begin{array}{l}\text { Employment status } \\
\text { Currently working } \\
\text { Retired } \\
\text { Other }\end{array}$ & $\begin{array}{l}9(5.9) \\
119(77.8) \\
25(16.2)\end{array}$ & \\
\hline $\begin{array}{l}\text { Medical insurance } \\
\text { No insurance } \\
\text { URMI and NRCMI } \\
\text { Free Medical Service } \\
\text { Medical Insurance outside } \\
\text { Beijing }\end{array}$ & $\begin{array}{l}17(I I . I) \\
115(75.2) \\
13(8.5) \\
8(5.2)\end{array}$ & \\
\hline $\begin{array}{l}\text { Smoking status } \\
\text { Never-smoker } \\
\text { Ex-smoker } \\
\text { Current-smoker } \\
\text { Smoking index (pack year) }\end{array}$ & $\begin{array}{l}32(20.9) \\
76(49.7) \\
45(29.4) \\
30.0[20.0,46.3]\end{array}$ & $2.5-112.0$ \\
\hline
\end{tabular}

Notes: Data are presented as median [25th, 75th percentiles] or $n$ (\%); ${ }^{2}$ Smoking index was calculated in current- and ex-smokers.

Abbreviations: BMI, body mass index; URMI, Urban Residents Medical Insurance; NRCMI, New Rural Cooperative Medical Insurance.

long-term personalized action plan provided by their doctors. Besides, 23 patients (15.0\%) ever attended patient education sessions and only $3(2.0 \%)$ ever sought online medical consultation for COPD (Table 2).

During the COVID-19 epidemic from January 25 to April 25, 2020, 55.6\% (85/153) of the patients did not go to any medical facilities, while $44.4 \%(68 / 153)$ visited Respiratory Clinics for regular follow-up, medicine prescription or symptom aggravation. Twenty patients (13.1\%) reported that they worried about the insufficient amount of maintenance medication and $10(6.5 \%)$ had to reduce 
Table 2 Medical History, Medications and Management of COPD Before the COVID-19 Epidemic

\begin{tabular}{|c|l|}
\hline Variables & $\begin{array}{l}\text { Median [25th, } \\
\text { 75th Percentiles] } \\
\text { or N (\%) }\end{array}$ \\
\hline History of COPD (year) & $5.0[3.0,8.0]$ \\
\hline Exacerbation in the past year & \\
Frequency of exacerbation (/year) & $129(84.3)$ \\
0 & $17(11.1)$ \\
I & $7(4.6)$ \\
\hline Hospitalization due to exacerbation & $135(88.2)$ \\
0 & $18(11.8)$ \\
$\geq 1$ & $6(3.9)$ \\
\hline Pharmacological treatment & $2(1.3)$ \\
Inhaled SABA & $93(60.8)$ \\
Inhaled SAMA & $88(57.5)$ \\
ICS/LABA & $12(7.8)$ \\
LAMA & \\
Oral theophylline & $23(15.0)$ \\
\hline Non-pharmacological management and & $3(2.0)$ \\
health behavior & $22(14.4)$ \\
Ever attending any education sessions & \\
Ever consulting respiratory specialists online \\
Having a long-term personalized action plan
\end{tabular}

Note: Data are presented as median [25th, 75th percentiles] or $\mathrm{n}(\%)$. Abbreviations: COPD, chronic obstructive pulmonary disease; COVID-19, coronavirus disease 2019; SABA, short-acting $\beta$-agonist; SAMA, short-acting muscarinic antagonist; ICS, inhaled corticosteroid; LABA, long-acting $\beta$-agonist; LAMA, longacting muscarinic antagonist.

medication dosing (1 patient) or stop taking medicine $(9$ patients). Additionally, 10 patients (6.5\%) expressed concerns for exacerbation of COPD. Compared to that before the COVID-19 epidemic, fewer patients $(75.2 \%, 115 / 153)$ maintained their pharmacological treatment, with a slight decrease of patients taking ICS/LABA (53.6\%) and LAMA (56.9\%). Among the patients who had continued their longterm pharmacological treatment (including 115 patients who maintained their pharmacological treatment and 1 patient who reduced his medication dosing, $\mathrm{n}=116$ ), $2.6 \%, 37.1 \%$, $33.6 \%$ and $26.7 \%$ of them had prescriptions for 2 weeks, 1 month, 2 months and 3 months, respectively (Table 3). Four patients (2.6\%) sought online consultation for COPD during the epidemic. Comparison of maintenance medications and online consultation before and during the epidemic is shown in Figure 1.

During the epidemic, respiratory symptoms were assessed by mMRC dyspnea scale and CAT score. Most of the patients $(76.5 \%, 117 / 153)$ had a low symptom burden,
Table 3 Medications, Management and Healthcare Utilization of COPD During the COVID-19 Epidemic

\begin{tabular}{|l|l|}
\hline Variables & N (\%) \\
\hline $\begin{array}{l}\text { Times of visiting to any hospital } \\
0\end{array}$ & $85(55.6)$ \\
I 2 & $51(33.3)$ \\
\hline Causes of visiting Respiratory Clinic in any hospital ${ }^{\text {a }}$ & \\
Getting medicine for COPD & \\
Review and assessment of COPD & $60(88.2)$ \\
Aggravation of respiratory symptoms & $4(5.9)$ \\
\hline Pharmacological treatment & $4(5.9)$ \\
\hline Inhaled SABA & \\
Inhaled SAMA & $4(2.6)$ \\
ICS/LABA & $2(1.3)$ \\
LAMA & $82(53.6)$ \\
Oral theophylline & $87(56.9)$ \\
\hline The doses of medicine prescribed in one outpatient visit & \\
2 weeks & $9(5.9)$ \\
\hline I month & $3(2.6)$ \\
2 months & $43(37.1)$ \\
3 months & $39(33.6)$ \\
\hline
\end{tabular}

Notes: Data are presented as $\mathrm{n}(\%) ;{ }^{\mathrm{a}}$ This was calculated in patients who ever visited Respiratory Clinic in any hospital $(n=68)$; ${ }^{\text {b }}$ This was calculated in patients having long-term pharmacological treatment $(n=116)$.

Abbreviations: COPD, chronic obstructive pulmonary disease; COVID-19, coronavirus disease 2019; SABA, short-acting $\beta$-agonist; SAMA, short-acting muscarinic antagonist; ICS, inhaled corticosteroid; LABA, long-acting $\beta$-agonist; LAMA, longacting muscarinic antagonist.

with a CAT score $<10$ during the epidemic. Eighty-five patients $(55.6 \%)$ had a mMRC score $<2$ (Table 4). During the COVID-19 epidemic, 45 patients (29.4\%) reported worsening of respiratory symptoms. Increased sputum volume, dyspnea and cough were the most common symptoms. In these patients, only $7(15.6 \%, 7 / 45)$ went to hospital to seek further medical care, 4 to the Respiratory Clinic, 2 to the Emergency Department and 1 hospitalized due to severe exacerbation. A large proportion $(55.5 \%, 25 / 45)$ of the patients who experienced respiratory symptom aggravation were concerned about cross-infection of COVID-19 in the hospital and the remaining $(28.8 \%, 13 / 45)$ thought that their symptoms were not serious and took more medications by themselves (Table 5). In the patients who had to reduce medication dosing or stop taking medicine during the epidemic, $30.0 \%(3 / 10)$ experienced respiratory symptom worsening.

Compared with patients without respiratory symptom worsening, more patients with respiratory worsening had CAT $\geq 10(15.0 \%, 16 / 108$ vs $42.2 \%, 19 / 45, P<0.001)$ and 


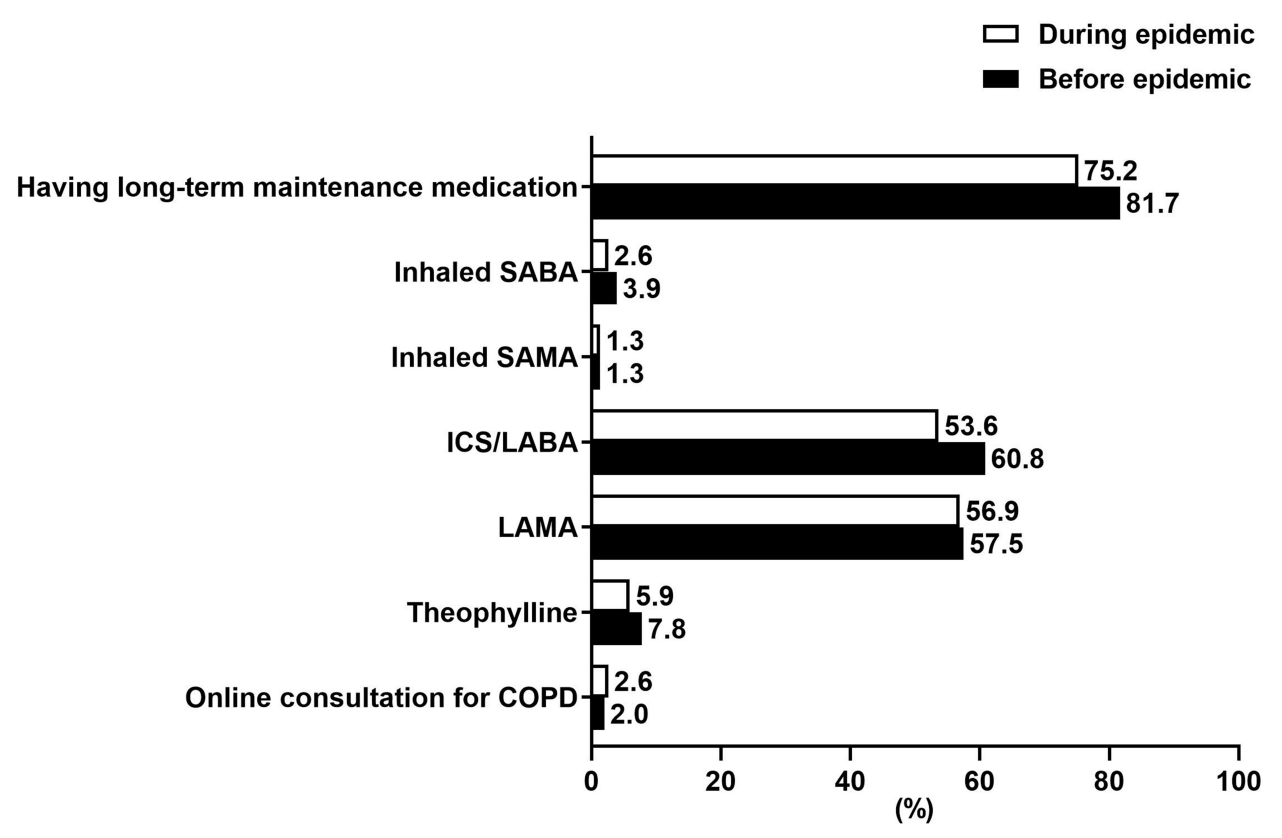

Figure I Comparison of maintenance medications and online consultation before and during the COVID-19 epidemic.

Abbreviations: COVID-19, coronavirus disease 2019; SABA, short-acting $\beta$ agonist; SAMA, short-acting muscarinic antagonist; ICS, inhaled corticosteroid; LABA, longacting $\beta$-agonist; LAMA, long-acting muscarinic antagonist; COPD, chronic obstructive pulmonary disease.

were frequent exacerbators in the past year $(1.9 \%, 2 / 108$ vs $11.1 \%, 5 / 45, P=0.024)$. Age, sex, body mass index, smoking status and medication treatment were not statistically different between patients with and without respiratory worsening (Table 6).

\section{Discussion}

In this cross-sectional survey by phone call, we found that, during the COVID-19 epidemic in Beijing, most of our COPD patients maintained their pharmacological treatment and had a low symptom burden as assessed by

Table 4 Assessment of Current Respiratory Symptoms

\begin{tabular}{|c|l|}
\hline Variables & n (\%) \\
\hline Current respiratory symptoms & \\
Modified MRC dyspnea scale & \\
0 & $35(22.9)$ \\
1 & $50(32.7)$ \\
2 & $33(21.6)$ \\
3 & $19(12.4)$ \\
4 & $16(10.5)$ \\
\hline CAT score & \\
$<10$ & $117(76.5)$ \\
$\geq 10$ & $36(23.5)$ \\
\hline
\end{tabular}

Note: Data are presented as $\mathrm{n}(\%)$.

Abbreviations: MRC, Medical Research Council; CAT, COPD Assessment Test; COPD, chronic obstructive pulmonary disease.
CAT. However, there were a minority of patients who had to reduce or stop taking medications due to concerns about a shortage of maintenance medications. Importantly, $29.4 \%(45 / 153)$ of the patients reported worsening of respiratory symptoms, but only $15.6 \%$ (7/45) sought medical care in hospitals, while most of them expressed concerns about cross-infection in the hospital or had mild symptoms which were managed by themselves.

During the 3 months of COVID-19 epidemic, most of our COPD patients were stable and had mild-to-moderate respiratory symptoms. More than $75 \%$ of these patients

Table $\mathbf{5}$ Changes of Respiratory Symptoms and the Response of the Patients During the COVID-19 Epidemic

\begin{tabular}{|l|l|}
\hline Variables & N (\%) \\
\hline Worsening of respiratory symptoms & $45(29.4)$ \\
Purulent sputum & $8(5.2)$ \\
Increased sputum volume & $22(14.4)$ \\
Increased dyspnea & $21(13.7)$ \\
Increased cough & $15(9.8)$ \\
Fever & $2(1.3)$ \\
\hline Visiting to hospitals due to respiratory symptoms ${ }^{\text {a }}$ & \\
Yes & $7(15.6)$ \\
No & $38(84.4)$ \\
\hline
\end{tabular}

Notes: Data are presented as $\mathrm{n}(\%)$; ${ }^{\mathrm{a}}$ This was calculated in patients with worsening of respiratory symptoms $(n=45)$.

Abbreviation: COVID-19, coronavirus disease 2019. 
Table 6 Comparison of Clinical Characteristics Between the Patients with and without Respiratory Symptoms Worsening

\begin{tabular}{|c|c|c|c|}
\hline & \multicolumn{2}{|c|}{$\begin{array}{l}\text { Respiratory } \\
\text { Symptoms Worsening }\end{array}$} & \multirow[t]{2}{*}{$P$-value } \\
\hline & $\begin{array}{l}\text { No }(n= \\
108)\end{array}$ & $\begin{array}{l}\text { Yes }(n= \\
45)\end{array}$ & \\
\hline Age (years) & $71.8 \pm 9.6$ & $72.5 \pm 10.6$ & 0.679 \\
\hline Male & $94(87.0)$ & $36(80.0)$ & 0.267 \\
\hline BMI $\left(\mathrm{kg} / \mathrm{m}^{2}\right)$ & $23.4 \pm 2.87$ & $22.9 \pm 3.3$ & 0.312 \\
\hline \multicolumn{4}{|l|}{ Smoking status } \\
\hline Never-smoker & $21(19.4)$ & II (24.4) & 0.301 \\
\hline Ex-smoker & $58(53.7)$ & $18(40.0)$ & \\
\hline Current-smoker & $29(26.9)$ & $16(35.6)$ & \\
\hline \multicolumn{4}{|l|}{ CAT score } \\
\hline$<10$ & 91 (85.0) & $26(57.8)$ & $<0.001$ \\
\hline$\geq 10$ & $16(15.0)$ & $19(42.2)$ & \\
\hline \multicolumn{4}{|c|}{$\begin{array}{l}\text { Frequency of exacerbation } \\
\text { (/year) }\end{array}$} \\
\hline $0-1$ & $106(98.1)$ & 40 (88.9) & 0.024 \\
\hline$\geq 2$ & $2(1.9)$ & $5(11.1)$ & \\
\hline \multicolumn{4}{|l|}{ Medications } \\
\hline SABA & $2(1.9)$ & $2(4.4)$ & $0.58 I$ \\
\hline SAMA & I (0.9) & I (2.2) & 0.503 \\
\hline ICS/LABA & $58(53.7)$ & $24(53.3)$ & 0.967 \\
\hline LAMA & $61(56.5)$ & $26(57.8)$ & 0.883 \\
\hline Theophylline & $4(3.7)$ & $5(11.1)$ & 0.125 \\
\hline
\end{tabular}

Note: Data are presented as mean \pm standard deviation or $n(\%)$.

Abbreviations: BMI, body mass index; CAT, COPD Assessment Test; COPD, chronic obstructive pulmonary disease; SABA, short-acting $\beta$-agonist; SAMA, shortacting muscarinic antagonist; ICS, inhaled corticosteroid; LABA, long-acting $\beta$ agonist; LAMA, long-acting muscarinic antagonist.

continued their maintenance therapy, mostly with ICS/ LABA and/or LAMA, which is consistent with current guidelines. ${ }^{1}$ Compared with Copenhagen General Population Study, ${ }^{10}$ the use rates of ICS/LABA and LAMA in our study were relevantly high, contributing to the maintenance of disease stability.

In our survey, although nearly $30 \%$ of the patients had respiratory symptom worsening, only three patients had severe exacerbation requiring visiting to Emergency Department or hospitalization. The majority of our patients did not need to seek medical care in hospitals and some of them could have their symptoms relieved by taking more medications. The lower rate of severe exacerbation in our study population might be due to social distancing, public hygiene measures and wearing of masks when going out in public, thereby reducing infection-induced COPD exacerbations.
It needs to be noted that, for patients experiencing worsening of respiratory symptoms, a large proportion expressed worries about the risk of exposure to COVID19 and therefore did not go to the hospital, but had medications step-up by themselves and experienced symptom alleviation, indicating that optimal selfmanagement outside hospital can be useful for those patients with mild exacerbation. A recent report from American Thoracic Society Patient Education emphasized that an action plan for COPD patients is important and helps patients to manage the lung condition and monitor the symptoms. ${ }^{11}$ This report also suggested that patients should maintain their medicines as directed and not delay getting refills. We found that patients experiencing a worsening of respiratory symptoms had greater CAT score and more COPD exacerbations in the past year, suggesting that patients with these high-risk factors should keep maintenance therapy and be monitored carefully.

In our survey, very few patients utilized online medical services for disease assessment and follow-up, although it was not difficult to acquire these services. Advanced age and education level of the COPD patients may hinder the use of telehealth, which is encouraged in epidemic emergencies when outpatient service should be prioritized for those who have exacerbations. ${ }^{12,13}$ In fact, a meta-analysis showed that telemedicine improved the quality of life and reduced the rates of hospitalization in COPD patients. ${ }^{14}$

Tobacco exposure is an important risk factor for the development of COPD. ${ }^{15}$ Nearly one half of the patients in our study were former-smokers. This was different from other previous large-scale cross-sectional studies, in which the prevalence of former-smokers in COPD population was less than $20 \%{ }^{3,16}$ However, our patients were elderly with a median age of more than 70 years. Older patients with COPD were more likely to quit smoking than younger patients. ${ }^{17}$ A large-scale epidemiological investigation in China showed that the successful smoking cessation rate in COPD patients was higher in those living in urban area and increased with age. In patients aged $\geq 70$ years, the smoking cessation rate was up to $36.4 \%{ }^{18}$ The high proportion of patients who had quit smoking may explain partly the low symptom burden of our study population.

Our study had several limitations. As a single-centered, cross-sectional telephone survey, the sample size was relatively small and recall bias could not be avoided. The majority of the patients were in advanced age with a median of $\geq 70$, and therefore data from individuals ranging 
from 40 to 60 years old were scarce. Finally, the study period was in spring, while it is well known that the rate and severity of COPD exacerbations vary with seasons. ${ }^{19}$

\section{Conclusions}

During the COVID-19 epidemic from January to April in Beijing, most of our patients with COPD maintained their long-term pharmacological treatment and had mild-tomoderate respiratory symptoms. Approximately $30.0 \%$ of the COPD patients experienced worsening of respiratory symptoms, but most of them did not seek medical care in the hospital due to concerns about cross-infection or successful self-management. Newer healthcare modalities such as telemedicine or online consultation may be needed for COPD patients during emergency periods.

\section{Abbreviations}

COPD, chronic obstructive pulmonary diseases; GOLD, Global Initiative for Chronic Obstructive Lung Disease; ICS, inhaled corticosteroids; LABA, long-acting $\beta 2$ agonist; SABA, short-acting $\beta$-agonist; BMI, body mass index; URMI, Urban Residents Medical Insurance; NRCMI, New Rural Cooperative Medical Insurance; MRC, Medical Research Council; CAT, COPD Assessment Test; COVID19, Coronavirus Disease-2019.

\section{Data Sharing Statement}

The data that supports the findings of this study will not be shared openly with other third parties due to contractual statements related to intellectual property, confidentiality, and proprietary rights.

\section{Ethics Approval and Informed Consent}

The study protocol was approved by the Independent Ethics Committee of the Peking University Third Hospital (IRB00006761-M2020189). Informed consent was informed by telephone and oral consents were obtained from the patients.

\section{Author Contributions}

All authors made a significant contribution to the work reported, whether that is in the conception, study design, execution, acquisition of data, analysis and interpretation, or in all these areas; took part in drafting, revising or critically reviewing the article; gave final approval of the version to be published; have agreed on the journal to which the article has been submitted; and agree to be accountable for all aspects of the work.

\section{Funding}

This study was supported by the National Natural Science Foundation of China. [No. 81700039].

\section{Disclosure}

The authors have no conflict of interest in this work.

\section{References}

1. Global Strategy for the Diagnosis. Management and prevention of chronic obstructive pulmonary disease, Global initiative for chronic obstructive lung disease (GOLD). 2020. Available from: http://www. goldcopd.org/. Accessed January 20, 2020.

2. Adeloye D, Chua S, Lee C, et al. Global and regional estimates of COPD prevalence: systematic review and meta-analysis. $J$ Glob Health. 2015;5(2):020415. doi:10.7189/jogh.05.020415

3. Wang C, Xu J, Yang L, et al. Prevalence and risk factors of chronic obstructive pulmonary disease in China (the China pulmonary health [CPH] study): a national cross-sectional study. Lancet. 2018;391 (10131):1706-1717. doi:10.1016/S0140-6736(18)30841-9

4. Zhao Q, Meng M, Kumar R, et al. The impact of COPD and smoking history on the severity of Covid-19: a systemic review and meta-analysis. J Med Virol. 2020. doi:10.1002/jmv.25967

5. Wang L, He W, Yu X, et al. Coronavirus disease 2019 in elderly patients: characteristics and prognostic factors based on 4-week follow-up. $J$ Infect. 2020;80(6):639-645. doi:10.1016/j.jinf.2020. 03.019

6. Chronic obstructive pulmonary disease group of Chinese Thoracic Society, Chronic obstructive pulmonary disease of Chinese Association of Chest Physician. [Medical management and prevention instruction of chronic obstructive pulmonary disease during the coronavirus disease 2019 epidemic]. Zhonghua Jie He Hе Ни Xi Za Zhi. 2020;43:E034.

7. GOLD. COVID-19 Guidance. Available from: http://www.goldcopd. org/. Accessed May 17, 2020.

8. Bestall JC, Paul EA, Garrod R, et al. Usefulness of the medical research council (MRC) dyspnoea scale as a measure of disability in patients with chronic obstructive pulmonary disease. Thorax. 1999;54(7):581-586. doi:10.1136/thx.54.7.581

9. Jones PW, Harding G, Berry P, et al. Development and first validation of the COPD assessment test. Eur Respir J. 2009;34(3):648-654. doi:10.1183/09031936.00102509

10. Ingebrigtsen TS, Marott JL, Nordestgaard BG, et al. Low use and adherence to maintenance medication in chronic obstructive pulmonary disease in the general population. J Gen Intern Med. 2015;30 (1):51-59. doi:10.1007/s11606-014-3029-0

11. Sockrider M, Tal-Singer R. Managing your chronic lung disease during the COVID-19 pandemic. Am J Respir Crit Care Med. 2020;202(2):5-6. doi:10.1164/rccm.2020C8

12. Centers for Disease Control and Prevention (U.S.). Coronavirus disease 2019 (COVID-19)/people who need extra precautions/people who are at higher risk/people with moderate to severe asthma. Available from: https://www.cdc.gov/coronavirus/2019-ncov/needextraprecautions/index.html. Accessed May 9, 2020.

13. Shaker MS, Oppenheimer J, Grayson M, et al. COVID-19: pandemic contingency planning for the allergy and immunology clinic. J Allergy Clin Immunol Pract. 2020;8(5):1477-1488.e5. doi:10.10 16/j.jaip.2020.03.012 
14. Liu F, Jiang Y, Xu G, Ding Z. Effectiveness of telemedicine intervention for chronic obstructive pulmonary disease in China: a systematic review and meta-analysis. Telemed $J$ E Health. 2020;26(9):1075-1092. doi:10.1089/tmj.2019.0215

15. Soriano JB, Kendrick PJ, Paulson KR; GBD Chronic Respiratory Disease Collaborators. Prevalence and attributable health burden of chronic respiratory diseases, 1990-2017: a systematic analysis for the global burden of disease study 2017. Lancet Respir Med. 2020;8 (6):585-596. doi:10.1016/S2213-2600(20)30105-3

16. Fang L, Gao P, Bao H, et al. Chronic obstructive pulmonary disease in China: a nationwide prevalence study. Lancet Respir Med. 2018;6 (6):421-430. doi:10.1016/S2213-2600(18)30103-6
17. Tøttenborg SS, Thomsen RW, Johnsen SP, et al. Determinants of smoking cessation in patients with COPD treated in the outpatient setting. Chest. 2016;150(3):554-562. doi:10.1016/j.chest.2016.05.020

18. Fan J, Cong S, Wang $\mathrm{N}$, et al. [Smoking cessation in chronic obstructive pulmonary disease patients aged 40 years or older in China, 2014-2015]. Zhonghua Liu Xing Bing Xue Za Zhi. 2020;41 (7):1021-1027.

19. So JY, Zhao H, Voelker H, et al. Seasonal and regional variations in chronic obstructive pulmonary disease exacerbation rates in adults without cardiovascular risk factors. Ann Am Thorac Soc. 2018;15 (11):1296-1303. doi:10.1513/AnnalsATS.201801-070OC

\section{Publish your work in this journal}

The International Journal of COPD is an international, peer-reviewed journal of therapeutics and pharmacology focusing on concise rapid reporting of clinical studies and reviews in COPD. Special focus is given to the pathophysiological processes underlying the disease, intervention programs, patient focused education, and self management protocols. This journal is indexed on PubMed Central, MedLine and CAS. The manuscript management system is completely online and includes a very quick and fair peer-review system, which is all easy to use. Visit http://www.dovepress.com/testimonials.php to read real quotes from published authors. 